\title{
Isolated operation of wind energy system in critical micro-grid
}

\author{
A. Peña Asensio ${ }^{1}$, M. Garcia-Plaza ${ }^{1}$, S. Arnaltes Gómez ${ }^{1}$, J.L. Rodriguez-Amenedo ${ }^{1}$, J. Eloy-García \\ Carrasco $^{1}$, J. Alonso-Martinez ${ }^{1}$ \\ ${ }^{1}$ Department of Electrical Engineering \\ Carlos III University \\ Campus of Leganes - Leganes, 28911 Madrid (Spain) \\ Phone number: +34 916244050, e-mail: anpenaa@ing.uc3m.es
}

\begin{abstract}
This paper analyses the possibility of forming an isolated microgrid using a Wind Energy Conversion System (WECS) to supply the loads and control the microgrid voltage and frequency. The proposed scheme uses a diode rectifier and a Voltage Sourced Converter (VSC) to control the WECS instead of the most common back-to-back structure with two VSCs. Wind turbine pitch control is used in a novel way in order to ensure active power balance. To validate the presented algorithms, experimental results from a low power test-rig, which includes a wind turbine emulation system, have been obtained.
\end{abstract}

\section{Key words}

Microgrids, Wind Energy, Stand-alone, Wind Turbine Emulation.

\section{Introduction}

Microgrids have introduced a new way of looking at distributed generation. They are composed of different load, generation and energy storage systems which can operate as a single controllable group due to their advanced internal regulation. Advantages of these systems include avoidance of transmission lines, reduced financial risk, improvement of power quality and local integration of renewable energy [1]-[7].

However, there are some concerns regarding microgrids operation. The requirement of electronic interfaces makes the control more complex and introduces new challenges related to power quality [3], [8]. In addition, renewable energy integration makes microgrids dependent on weather conditions. These reasons highlight the necessity to investigate these systems, especially when it involves renewable energy sources.

Among renewable energies, wind energy is one of the most important, with more than 372 GW installed in 2014 [9]. Research and integration of wind energy conversion systems (WECSs) and voltage sourced converters (VSCs) control have increased the possibilities of these systems that cannot assure power quality generation by themselves [10].

Although in their most common application WECSs are prepared to give all the available power to the grid, in this paper a different approach is proposed in which the WECS is responsible of supplying only the power demanded by an isolated load. Therefore, this paper deals with the study of microgrids internal regulation systems by analysing a worst-case scenario where the WECS is responsible of maintaining the microgrid voltage and frequency.

A PMSG (Permanent Magnet Synchronous Generator) has been used in the WECS. Interest in this technology has grown in recent years as it allows for a more robust "direct drive" gearless drivetrain, by introducing a greater pole number in a lower volume [11], [12]. A common disadvantage of PMSGs has been the necessity of a fullpower converter structure. The most common solution is using two VSCs in a back-to-back topology. Other control schemes have been proposed which substitute the statorside VSC for a diode rectifier with a DC-DC conversion system, such as a chopper branch, for maximum power extraction [13]-[17].

In this paper, the WECS is controlled using a diode rectifier and a VSC, which can be a cheaper and more reliable option than the back-to-back or DC-DC conversion solutions. As will be discussed on section 2 , in this scheme the WECS is controlled by the pitch regulation of the turbine.

For test purposes, a hardware-in-the-loop wind turbine (WT) emulation system is developed which allows obtaining experimental results in a laboratory. It is based on the scheme developed in [18]. There have been other similar approaches as in [19] and [20].

The complete structure of the system can be seen in Fig. 1. 


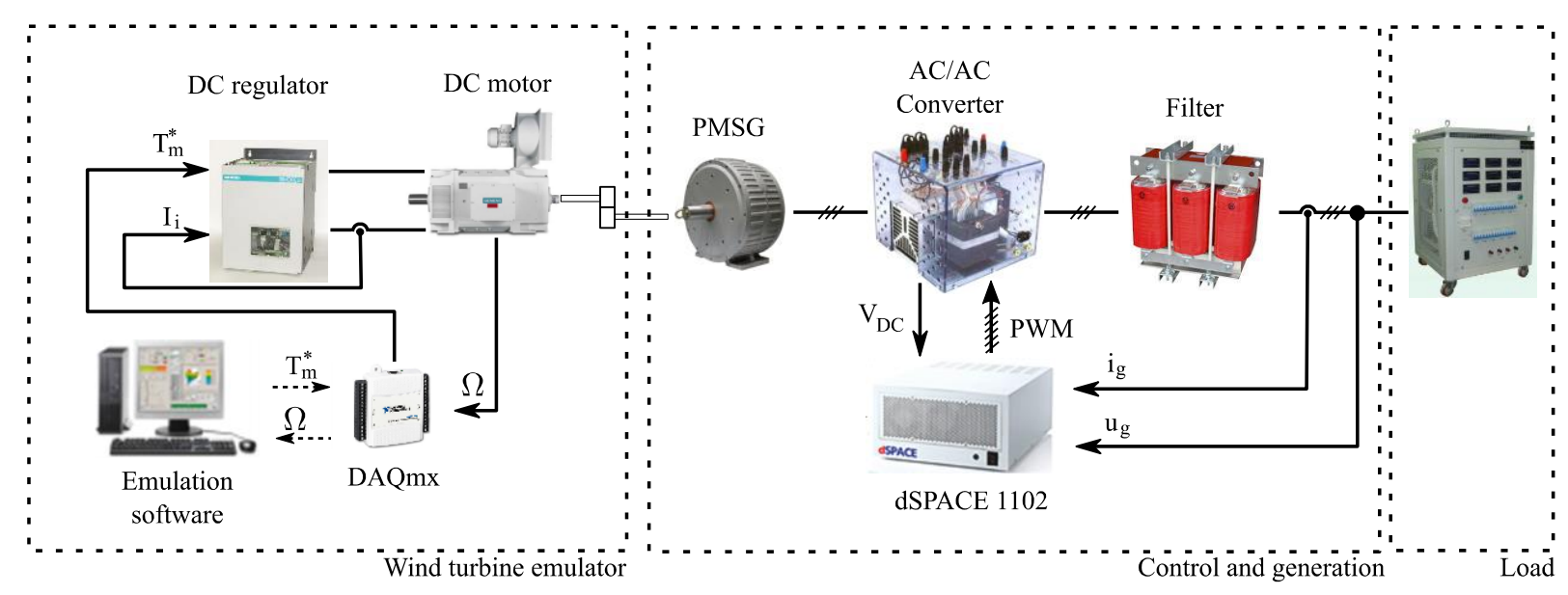

Fig. 1 System proposed in the paper.

\section{Wind turbine power control and emulation}

This section aims to present the fundamental WT and generator dynamics as well as expose the model used for the emulation system.

\section{A. Wind turbine power control}

WTs produce electricity by extracting kinetic energy from the wind. The instantaneous power extracted depends on the volume and speed of the air going through its area and on the blade design, as

$$
P=\frac{1}{2} \rho A v^{3} C_{p}(\lambda, \beta),
$$

where $\mathrm{Cp}$ is a power coefficient function of the tip speed ratio $\lambda$ and the pitch angle $\beta$ and includes the dynamic response of the turbine.

On grid-connected wind energy systems, $\beta$ is used to limit the power extracted at high wind speed. However, in this paper $\beta$ is the actuation parameter which ensures power balance between the WT and the load. As the rotor blades are to be moved, this actuation is normally limited to a variation form $5 \%$ to $10 \%$ [21], limiting the control time response.

For this time scale, a constant load performs as a constant power demand from the WT perspective as voltage variations are significantly faster. The variations of available power resulting from the wind will produce variations on the turbine rotation speed. This rotation speed must be controlled in order to ensure WT is stable in a wide range of wind speeds. To reduce the torque applied in the rotor, the optimal solution is to maintain the nominal rotation speed. The control loop used is depicted in Fig. 2, where the rate limiter represents the actuator dynamics.

This control loop can operate below nominal rotation speed, i.e. pitch angle control saturated at minimum value, for a limited range of wind speeds.

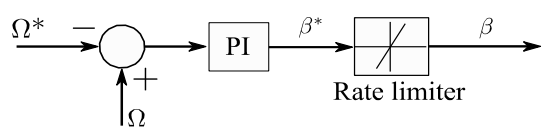

Fig. 2 Pitch angle control loop.

\section{B. Wind turbine emulation}

WT emulation is based on applying a torque in the axis of the PMSG which behaves as if it was produced by the wind. The emulation system uses both hardware and software elements.

Hardware includes a 1GG5 SIEMENS DC motor controlled by a commercial SIMOREG 6RA23s regulator. The reference for the SIMOREG controller is generated through a DAQmx USB-6009 model DAC (Digital to Analog Converter), from National Instruments. The full system is shown in Fig. 1.

The digital reference is generated from a LabVIEW program, running on a PC with a sample time of $100 \mathrm{~ms}$, which is enough for the turbine dynamics. This program is able to:

- Calculate the torque reference, considering the emulated wind speed and the turbine characteristics.

- Display a user-friendly HMI (Human-Machine Interface), as shown in Fig. 3.

- Adapt to different turbine parameters, which can be modified on-line through the interface of Fig. 4.

- $\quad$ Emulate the effect of WT inertia.

To emulate the effect of the inertia, it must be considered that the real system, which is desired to emulate, behaves as

$$
T_{m}-T_{e}=\frac{d \Omega}{d t}\left(J_{T}+J_{P M S G}\right),
$$

while the emulator behaves as 


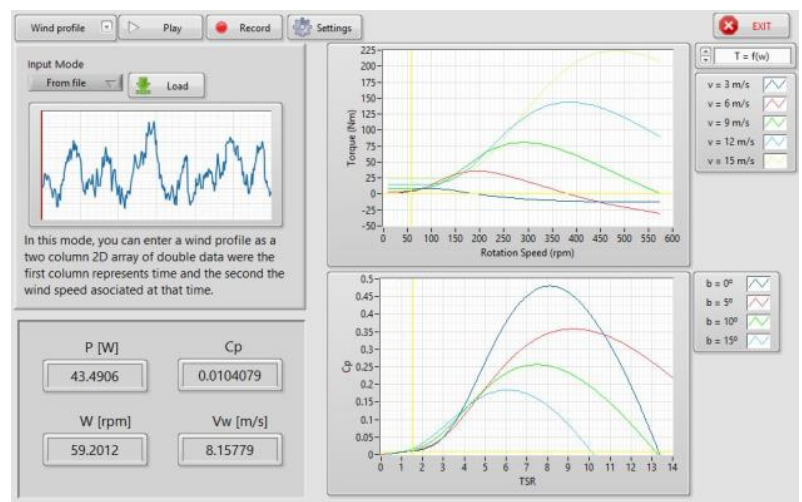

Fig. 3 Wind Turbine emulation software main interface.

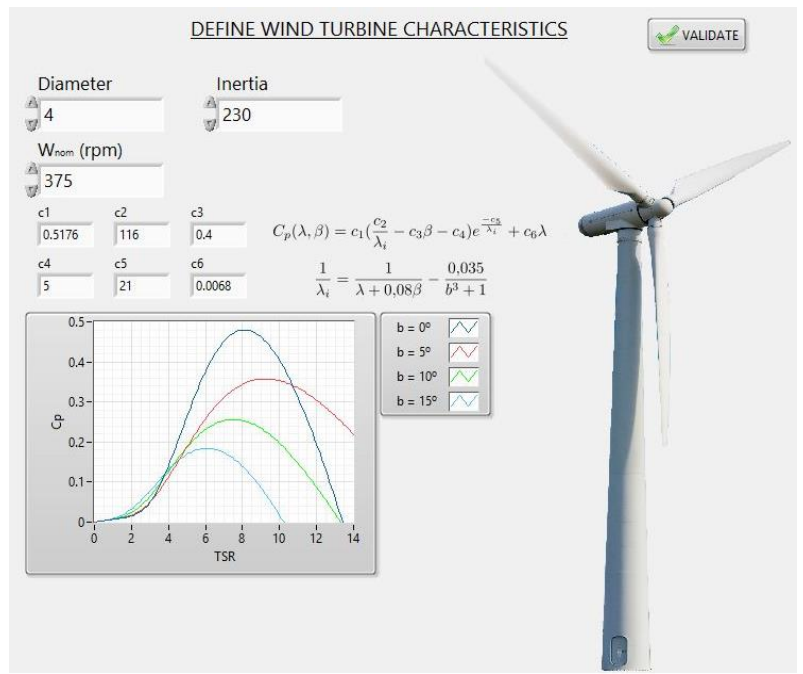

Fig. 4 Interface to select the emulated wind turbine characteristics.

$$
T_{m}-T_{e}=\frac{d \Omega}{d t}\left(J_{D C}+J_{P M S G}\right)
$$

where $\mathrm{Tm}$ is the torque that results of considering all other turbine characteristics, $\mathrm{J}_{\mathrm{T}}$ is the turbine inertia that must be emulated and $\mathrm{J}_{\mathrm{DC}}$ is the inertia of the actual DC machine. In view of equations (2) and (3), the torque reference for inertia emulation must be

$$
T_{r e f}=T_{m}-\frac{d \Omega}{d t}\left(J_{T}-J_{D C}\right) .
$$

\section{Generator characteristics}

The electrical behavior of a PMSG can be expressed as

$$
\vec{u}_{s}=R_{s} \vec{i}_{s}+L_{s} \frac{d}{d t} \vec{i}_{s}+\varphi \frac{d}{d t} e^{j \varepsilon},
$$

where subscript $\mathrm{s}$ indicates a variable referred to the stator, $\varphi$ is the total magnetic flux linkage, $\varepsilon$ is the angular position of the rotor and Ls includes all the induction effects of the generator.

From (5), the steady state model of the PMSG can be obtained. The steady-state model is useful to illustrate this application since the generator dynamics are significantly faster than WT ones. In this model the stator voltage

$$
\vec{U}_{s}=R_{s} \vec{I}_{s}+j \omega L_{s} \vec{I}_{s}+j \omega \varphi,
$$

This relation demonstrates how, by keeping a constant speed on the wind turbine through the pitch control loop explained in section 2.A, the voltage on the stator terminal is also constant. Voltage amplitude will vary depending on power demand due to the currentdependent terms of equation (6).

\section{Converter Control}

As explained in section 1, the proposed scheme uses a diode rectifier in the stator side of the WECS. This implies that no control can be performed on the converter to modify the PMSG behavior. However, since the power extracted from the PSMG is determined by the load and the mechanical speed is controlled by the pitch regulation explained in section 2.A, there is no need for such control. If the WT speed is kept constant, by equation (6), the PMSG stator voltage will be constant and thus, due to the rectifier, the DC link voltage will be kept constant as well.

The aim of the VSC control system is thus to supply the power demanded by the load while maintaining a constant-amplitude, constant-frequency voltage on its terminals. For this purpose, a vector control in dq axis is implemented. This type of control allows for a reliable and simple control process since the three phase voltage is controlled through two independent SISO (Single Input Single Output) loops. Moreover, as this is the most common control mode used for grid connected converters, upgrades, such as an internal current loop, are widely known and hence can be easily introduced.

Since the voltage $\mathrm{Vg}$ is the control variable, the plant model will be strongly influenced by the load. In Fig. 5, a $\mathrm{dq}$ model for the case of a resistive load RL and an inductive filter $\mathrm{Lf}$ is represented.

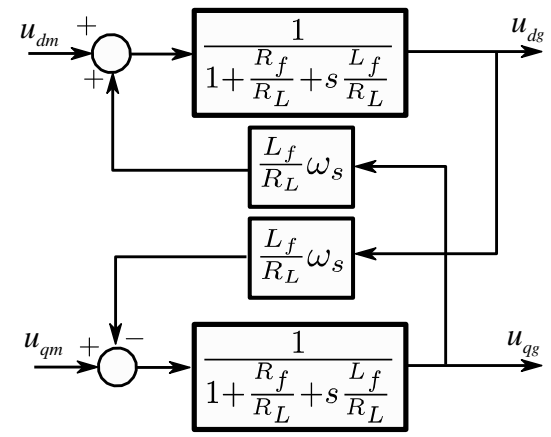

Fig. 5 dq axis plant model.

The reference for the dq to stationary axis transformation is generated based on the desired frequency. In Fig. 6 the control loop scheme is depicted.

The proposed control loop also ensures reactive power balance. This reactive power is supplied by the VSC and thus has no effect on the WT.

is directly dependent on the wind turbine speed. 


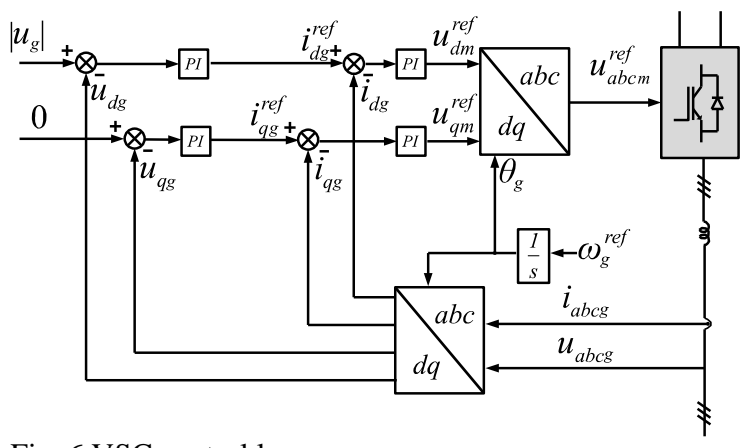

Fig. 6 VSC control loop.

\section{Result and Discussion}

Both real-time and simulation tests have been performed to validate the proposed algorithms using a set-up based on Fig. 1. Simulations were developed using MATLABSimulink in co-simulation with PSIM. Simulink, was used to program control algorithms whereas PSIM was used for the electrical circuit model implementation. The set-up used for real-time tests includes:

- INCLIN 3000 PMSG with Nd-Fe-B technology. Nominal parameters are $3000 \mathrm{VA}, 220 \mathrm{~V}, 375 \mathrm{rpm}$.

- SEMIKRON SEMITEACH, composed of three SKM 50GB123 IGBT single phase bridges plus three SKKD single phase diode rectifiers.

- DSPACE ds1102 digital control board. The sample time selected was $220 \mu$ s due to board limitations.

- WT emulation system as explained in section 2. For test purposes, a reduced inertia has been emulated.

The base values for per unit transformation are $S_{b}=3000$ $\mathrm{VA}, \mathrm{V}_{\mathrm{LL}, \mathrm{b}}=132.8 \mathrm{~V}$ and $\Omega_{\mathrm{b}}=375 \mathrm{rpm}$.

The proposed scheme has been analyzed through both wind and load variations. First, a load step is performed in simulation. Then, a more realistic approach is shown where the wind suffers a turbulent variation around $11 \mathrm{~m} / \mathrm{s}$ in the real time system.

\section{A. Response to load variations}

In spite of load variations, the VSC control system must be able to maintain constant voltage and frequency. Also, the pitch angle control must ensure steady-state power balance between generation and load to ensure a stable operation.

A 0.5 p.u to 0.75 p.u. load step has been performed. Results as shown in Fig. 7.

The power demanded by the load is initially obtained from the WT deceleration. In steady-state, the variation of the pitch angle $\beta$ balances generation and load and thus restores WT speed. Despite the DC-link voltage variation, due to WT speed variation, the voltage in the load terminals is kept constant even during the power transient.

The DC-link voltage amplitude does not return to its original value due to the stator voltage dependency with power extraction explained in section 2.C.
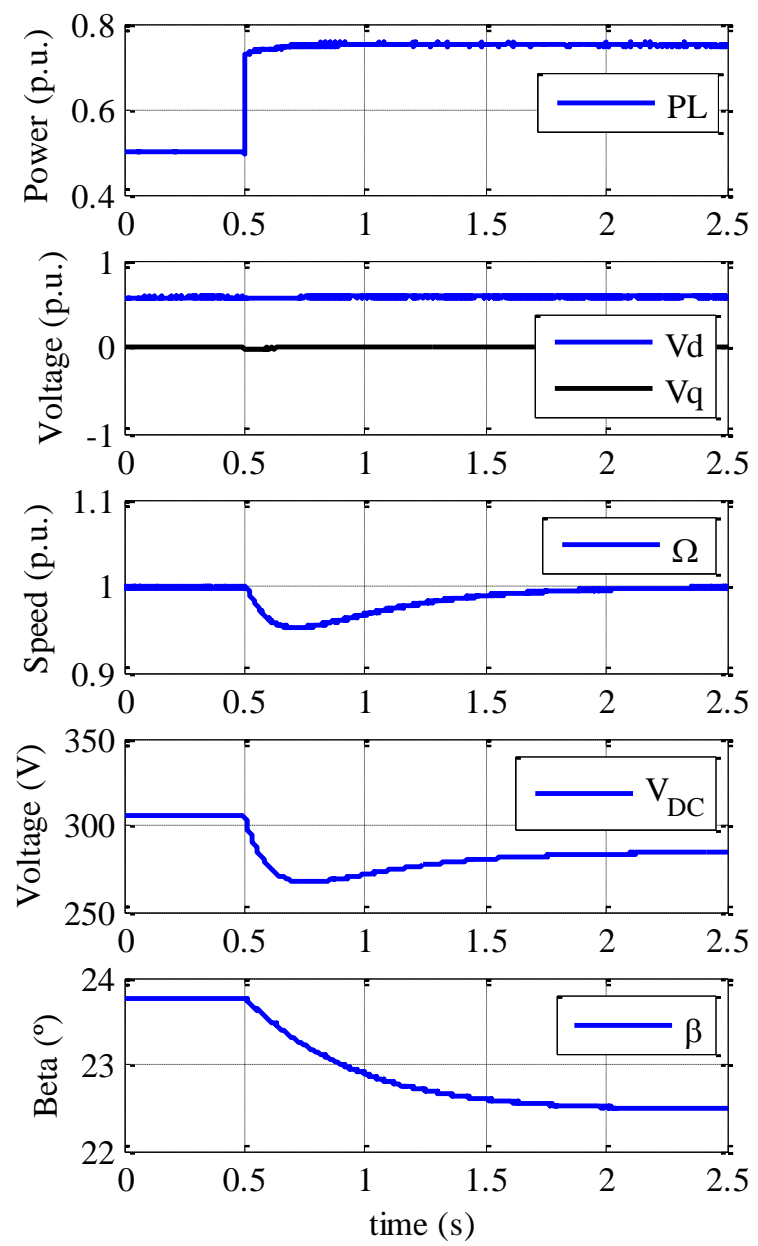

Fig. 7 Response to load step.

\section{B. Response to wind variations}

To study the system's response to wind variations, the wind profile of Fig. 8 has been used. The profile consists of a turbulent variation around $11 \mathrm{~m} / \mathrm{s}$, which is a realistic approach to an area with average wind speeds.

The pitch angle control keeps WT speed constant at its nominal value by following the wind variations.

\section{Conclusion}

According to the results presented in the paper, it can be concluded that:

- The pitch angle control loop is able to maintain the steady-state power balance between the WT and the load.

- The proposed VSC control scheme is able to maintain constant voltage and frequency, and thus ensure active and reactive power balance in the microgrid, despite wind or load variations.

- It is possible to use a diode rectifier instead of a more expensive VSC. 

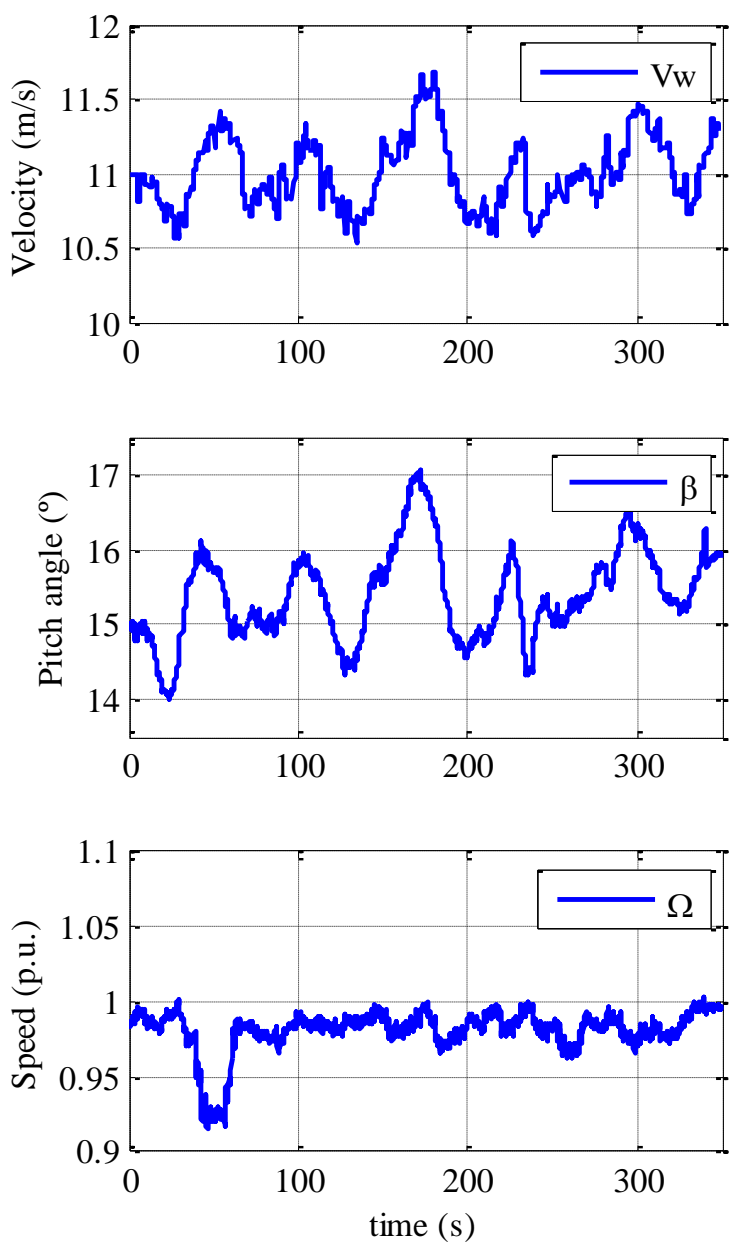

Fig. 8 Response to wind variations

\section{References}

[1] M. S. Mahmoud and F. M. Al-Sunni, Control and Optimization of Distributed Generation Systems. Springer, 2015.

[2] F. Blaabjerg, Z. Chen, and S. B. Kjaer, 'Power electronics as efficient interface in dispersed power generation systems', IEEE Trans. Power Electron., vol. 19, no. 5, pp. 1184-1194, Sep. 2004.

[3] R. H. Lasseter, 'MicroGrids', in IEEE Power Engineering Society Winter Meeting, 2002, 2002, vol. 1, pp. 305-308.

[4] P. Piagi and R. H. Lasseter, 'Autonomous control of microgrids', in 2006 IEEE Power Engineering Society General Meeting, 2006, p. 8 pp.-.

[5] F. Katiraei, M. R. Iravani, and P. W. Lehn, 'Micro-grid autonomous operation during and subsequent to islanding process', IEEE Trans. Power Deliv., vol. 20, no. 1, pp. 248-257, Jan. 2005.

[6] F. Katiraei and M. R. Iravani, 'Power Management Strategies for a Microgrid With Multiple Distributed Generation Units', IEEE Trans. Power Syst., vol. 21, no. 4, pp. 1821-1831, Nov. 2006.

[7] A. L. Dimeas and N. D. Hatziargyriou, 'Operation of a Multiagent System for Microgrid Control', IEEE Trans. Power Syst., vol. 20, no. 3, pp. 1447-1455, Aug. 2005.

[8] M. Meiqin, L. Chang, and D. Ming, 'Integration and intelligent control of micro-grids with multi-energy generations: A review', in 2008 IEEE International Conference on Sustainable Energy Technologies, 2008, pp. 777-780.
[9] Navigant Research, 'World Wind Energy Market Update 2015 - Executive Summary’. Mar-2015.

[10] R. Teodorescu, M. Liserre, and P. Rodríguez, 'Grid Converter Structures for Wind Turbine Systems', Grid Convert. Photovolt. Wind Power Syst., pp. 123-143.

[11] M. Chinchilla, S. Arnaltes, and J. C. Burgos, 'Control of Permanent-Magnet Generators Applied to VariableSpeed Wind-Energy Systems Connected to the Grid', IEEE Trans. Energy Convers., vol. 21, no. 1, pp. 130135, Mar. 2006.

[12] M. Sagawa and S. Fujimura, "New material for permanent magnets on a base of $\mathrm{Nd}$ and Fe', J. Appl. Phys., vol. 55, pp. 2083-2087, 1984.

[13] N. Yamamura, M. Ishida, and T. Hori, 'A simple wind power generating system with permanent magnet type synchronous generator', in Proceedings of the IEEE 1999 International Conference on Power Electronics and Drive Systems, 1999, vol. 2, pp. 849-854.

[14] Y. Higuchi, N. Yamamura, M. Ishida, and T. Hori, 'An improvement of performance for small-scaled wind power generating system with permanent magnet type synchronous generator', in 26th Annual Confjerence of the IEEE Industrial Electronics Society, 2000, 2000, vol. 2, pp. 1037-1043.

[15] K. Amei, Y. Takayasu, T. Ohji, and M. Sakui, 'A maximum power control of wind generator system using a permanent magnet synchronous generator and a boost chopper circuit', in Power Conversion Conference, 2002. PCC-Osaka 2002. Proceedings of the, 2002, vol. 3, pp. 1447-1452.

[16] W. Li, C. Abbey, and G. Joós, 'Control and Performance of Wind Turbine Generators based on Permanent Magnet Synchronous Machines Feeding a Diode Rectifier', in 37th IEEE Power Electronics Specialists Conference, 2006, 2006, pp. 1-6.

[17] E. Koutroulis and K. Kalaitzakis, 'Design of a maximum power tracking system for wind-energy-conversion applications', IEEE Trans. Ind. Electron., vol. 53, no. 2, pp. 486-494, Apr. 2006.

[18] M. Chinchilla, S. Arnaltes, and J. L. RodriguezAmenedo, 'Laboratory set-up for wind turbine emulation', in 2004 IEEE International Conference on Industrial Technology, 2004, vol. 1, pp. 553-557.

[19] R. Cardenas, R. Pena, G. M. Asher, and J. C. Clare, 'Experimental emulation of wind turbines and flywheels for wind energy applications', in European Power Electronics and Applications Conference, EPE2001, Graz, Austria, 2001, pp. 1-10.

[20] W. Li, D. Xu, W. Zhang, and H. Ma, 'Research on Wind Turbine Emulation based on DC Motor', in 2007 2nd IEEE Conference on Industrial Electronics and Applications, 2007, pp. 2589-2593.

[21] G. Abad, J. Lopez, M. Rodríguez, L. Marroyo, and G. Iwanski, Doubly fed induction machine: modeling and control for wind energy generation. 2011. 